\title{
Rancang Bangun Sistem Informasi Administrasi Pembayaran Spp dan Administrasi Sekolah Pada Smk Pgri 11 Ciledug menggunakan Metodologi Berorientasi Obyek
}

\author{
Siti Maryam \\ School of Information Systems, Universitas Bina Nusantara, Jakarta, Indonesia \\ sitimaryam@binus.edu
}

\begin{abstract}
Abstrak. Sistem pembinaan terpadu yang didukung oleh guru dan staff berpendidikan pada Sekolah Menengah Kejuruan (SMK) PGRI 11 CILEDUG, berupaya agar peserta didik yang diamanahkan dapat berkembang secara maksimal sehingga mereka akan menjadi insan-insan sukses yang dapat membangun peradaban bangsa dan masyarakat yang bertujuan menjadi sekolah yang dapat melahirkan generasi cerdas, kreatif, dan memiliki budi pekerti yang baik. Penyampaian laporan pembayaran yang tidak tepat waktu yang saat ini menjadi permasalahan yang dihadapi pada SMK PGRI 11 CILEDUG, disebabkan prosedur yang belum jelas, sehingga siswa dapat mengabaikan prosedur yang ada. Penulis mengambil judul "Rancangan Bangun Sistem Informasi Administrasi Pembayaran Spp Dan Administrasi Sekolah Dengan Metodologi Berorientasi Obyek”. Harapan dengan adanya rancangan bangun sistem informasi, dapat membantu staff administrasi SPP dapat menangani proses pembayaran dan dapat memperkecil kesalahan pencatatan data
\end{abstract}

Kata kunci: Sistem Administrasi Pembayaran SPP, Metodologi Berorientasi Obyek

\begin{abstract}
An integrated coaching system supported by educated teachers and staff at the CILEDUG 11 Vocational High School (SMK), seeks that the entrusted students can develop optimally so that they will become successful people who can build the nation's civilization and society aiming to become schools who can give birth to a generation of smart, creative, and have good character. Submitting a payment report that is not on time which is currently a problem faced by SMK PGRI 11 CILEDUG, due to unclear procedures, so students can ignore existing procedures. The author takes the title "Design of Building Information Systems for Spp Payment Administration and School Administration with Object Oriented Methodology". Hope with the design of information systems, can help SPP administrative staff can handle the payment process and can minimize data recording errors.
\end{abstract}

Keywords: SPP Payment Administration System, Object Oriented Methodology.

\section{Pendahuluan}

Memasuki era yang semakin canggih ini, ilmu pengetahuan dan teknologi, khususnya teknologi informasi berkembang dengan cepat dan menghasilkan inovasi baru. Komputer merupakan salah satu teknologi informasi yang telah banyak digunakan untuk mempermudah kehidupan manusia saat ini. Seluruh aspek kehidupan dapat menggunakan komputer untuk membantu atau mempermudah berbagai macam hal,mulai dari yang mudah seperti membuat ketikan biasa sampai yang sulit seperti pembuatan software. Di dalam dunia pendidikan, komputer dapat menjadi media pembelajaran yang baru.

Dalam dunia pendidikan seperti yang sedang meningkat saat ini, dunia pendidikan tidak memiliki sistem administrasi yang baik, yang akan mengakibatkan masalah serius. Terutama penyimpanan data, karena penyimpanan data yang tidak baik akan berakibat tidak akurat dan relevannya sebuah data. Terkait dengan hal ini, perlu dikembangkan sebuah sistem yang baik. Dimana nantinya akan mempercepat pekerjaan yang dilakukan, sehingga lebih menghemat waktu.

SMK PGRI 11 CILEDUG merupakan salah satu sekolah yangbelum menerapkan pencatatan pembayaran yang terkomputerisasi, sehingga menimbulkan resiko seperti kesalahan pencatatan data adminstrasi pembayaran.

\section{Bahan dan Metode: \\ 1. Konsep Dasar}

Sistem informasi merupakan hal penunjang yang sangat penting bagi semua tingkat manajemen di suatu organisasi dalam pengambilan keputusan. Menurut John W. Satzinger pada buku karangannya mendefinisikan sistem informasi sebagai: 
"sistem informasi didefinisikan sebagai kumpulan dari beberapa bagian yang saling berhubungan yang mengumpulkan, memproses, menyimpan, dan menyediakan, sebagai hasil dari informasi yang dibutuhkan untuk menyelesaikan bisnis".

\section{Analisa Sistem}

Analisa sistem adalah sebuah istilah yang secara kolektif mendeskripsikan tahap awal pengembangan sistem. Analisa sistem juga dapat diartikan sebagai pemisah dua hal dalam bagian-bagian tertentu. Bagian-bagian tersebut kemudian dipelajari dan dievaluasi untuk mengetahui apakah terdapat cara-cara yang lebih baik untuk memenuhi kebutuhan (Lonny, 2007). Berkaitan dengan permasalahan peluang dan tujuan untuk menganalisis aliran informasi antara manusia dengan komputer disebuah organisasi (Kendall, 2011).

\section{Analisa Berorientasi Obyek}

Konsep dasar berorientasi obyek mencapai puncaknya pada saat masalah analisis dan desain menjadi lebih diperhatikan daripada masalah coding. Secara spesifik, pengertian berorientasi obyek Sukamto dan Shalahuddin berorientasi objek pada buku karangannya yaitu: "Berorientasi obyek atau object oriented merupakan suatu pengembangan rekayasa perangkat lunak sebagi kumpulan obyek-obyek yang berisi data dan operasi yang berlaku saling berinteraksi satu sama lain".

\section{Perancangan Sistem Berorientasi Obyek}

Menurut Rosa (2013), diagram Unified Modeling Language (UML) adalah : "kebutuhan pemodelan visual untuk menspesifikasikan, menggambarkan, membangun, dan dokumentasi dari sistem perangkat lunak".

\section{Metode Penelitian}

Metode penelitian yang digunakan adalah SDLC atau system development life cycle yang teridir dari beberapa tahapan diantaranya adalah:
a. Planning
b. Analysis
c. Design
d. Implementation

\section{Hasil dan Pembahasan}

\section{Tinjauan Organisasi}

Sejarah SMK PGRI 11 CILEDUG SMK PGRI

11 Ciledug - Tangerang berdiri tepatnya pada tanggal 3 Januari 1976. Bertempat diruang pertemuan kegiatan kecamatan Ciledug tepatnya disebelah timur Danramil Kec.Ciledug Kab.Tangerang.SMK PGRI 11 Ciledug awalnya SMEA 9 Jakarta.

Terjadinya perubahan dari SMEA Persiapan Negeri Ciledug Kab. Tangerang. Pada waktu itu para siswa akan mengikuti ujian akhir banyak persyaratan untuk menginduk ke SMEA Negeri, akhirnya solusi yang mudah ditempuh agar para siswa mengikuti Ujian Akhir ke Yayasan Pembina Persekolahan PGRI Bandung Jl. Telaga Bodas No. 56 Bandung, terdaftarlah SMEA PGRI 11 Ciledug. SMEA PGRI urutan yang ke 11 di Bandung.

\section{Analisa Proses}

Bendahara meminta data siswa ke bagian kesiswaan, lalu bagian kesiswaan menyerahkan data siswa yang diminta ke bendahara. Setelah itu menyerahkannya kepada kolektor SPP, lalu kolektor SPP mengisi data siswa pada buku pembayaran untuk kemudian diserahkan kepada siswa/siswi, menyerahkan data siswa yang diminta ke bendahara.

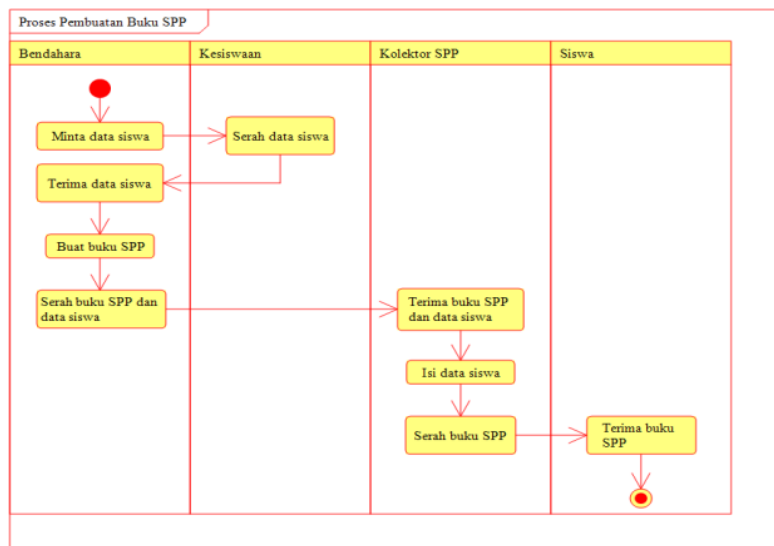

Gambar 1 : Activity Diagram Proses Pembuatan Kartu SPP

\section{Analisa Keluaran}

Analisa keluaran adalah analisa mengenai keluarankeluaran yang dihasilkan oleh proses-proses yang ada dalam sistem yang berjalan pada sistem administrasi pembayaran SPP dan administrasi sekolah pada SMK PGRI 11 Ciledug.

\section{Analisa Masukan}

Analisa masukan berisi gambaran masukan yang dihasilkan oleh sistem yang di analisa, dimana setiap masukan dapat dirinci

\section{Identifikasi Kebutuhan}

Setelah melakukan analisa proses bisnis serta mengidentifikasi masalah yang terjadi, selanjutnya adalah proses identifikasi kebutuhan. Berikut adalah hasil Analisa identifikasi kebutuhan yang diharapkan dapat menyelesaikan masalah yang ditemukan

6. Use Case Diagram

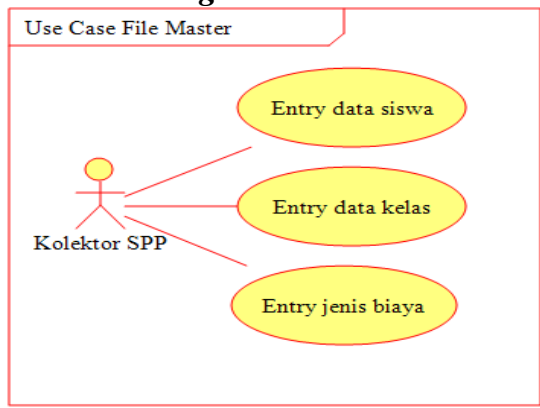

Gambar 2. Use Case Diagram Master 
Jurnal Keilmuan dan Aplikasi Teknik

UNISTEK, 2019, Vol. 6, No.1

\section{Rancangan Basis Data}

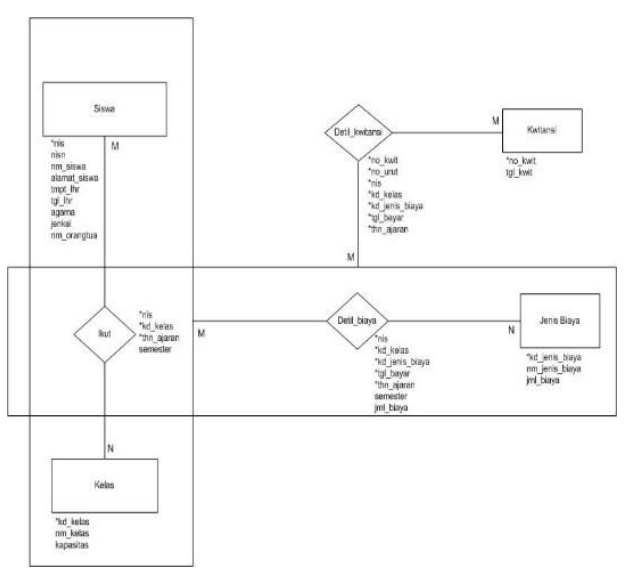

Gambar 3. Cara pembacaan hubungan antar entitas

$(\mathrm{M}: \mathrm{N})$ many to many : Hubungan entitas siswa dengan entitas kelas, 1 siswa dapat berada di banyak kelas 1 kelas dapat berisi banyak siswa. Spesifikasi basis data yang memberikan penjelasan secara detil tentang masingmasing basis data yang digunakan dalam rancangan sistem informasi Administrasi pembayaran SPP dan Administrasi Sekolah SMK PGRI 11 CILEDUG adalah sebagai berikut:

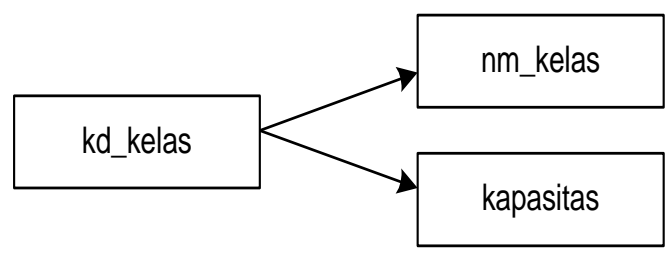

Gambar 4. Diagram Ketergantungan Fungsi Tabel Kelas

Tabel kelas sudah normal bentuk 1NF, karena sudah tidak ada atribut yang berulang, dan sudah normal bentuk $2 \mathrm{NF}$ karena sudah $1 \mathrm{NF}$ dan sudah tidak terdapat partial depedence, dan sudah ke dalam bentuk transitive depedence, dan tabel kelas telah normal bentuk $3 \mathrm{NF}$, karena sudah $2 \mathrm{NF}$ dan sudah tidak terdapat transitive dependence.
Tabel 1 Tabel Spesifikasi Basis Data Kelas

\begin{tabular}{|c|c|c|c|c|}
\hline No. & $\begin{array}{l}\text { Nama } \\
\text { Field }\end{array}$ & Jenis & Lebar & Keterangan \\
\hline 1. & kd_kelas & Char & 4 & $\begin{array}{l}\text { Berisi } 4 \text { digit } \\
\text { kode kelas terdiri } \\
\text { dari huruf dan } \\
\text { angka }\{\text { KL01 }\}\end{array}$ \\
\hline 2. & nm_kelas & Char & 31 & $\begin{array}{l}\text { Berisi nama kelas } \\
\text { terdiri dari angka, } \\
\text { huruf dan romawi } \\
\text { X-XII, A-Z, 0-9 }\end{array}$ \\
\hline 3. & kapasitas & Char & 2 & $\begin{array}{l}\text { Berisi kapasitas } \\
\text { kelas terdiri dari } \\
\text { angka } 0-9\end{array}$ \\
\hline
\end{tabular}

\section{Rancangan Antar Muka}

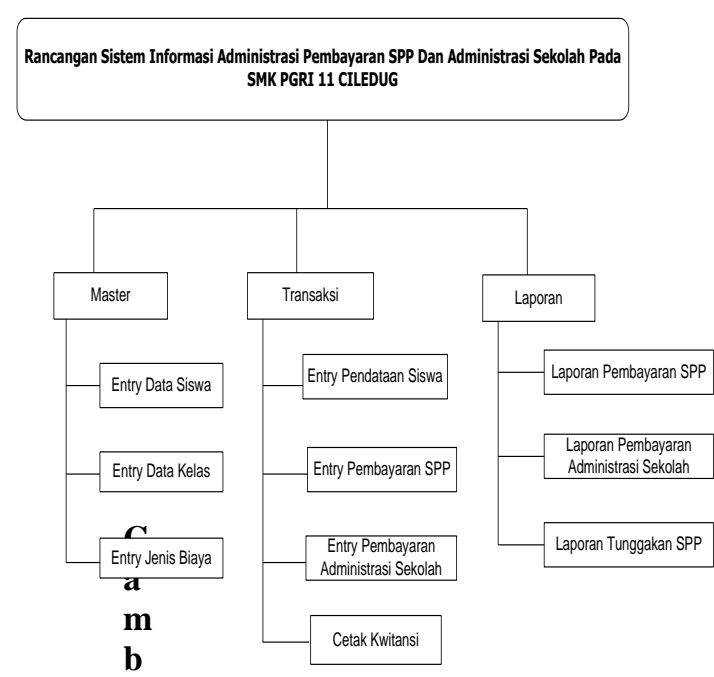

Gambar 5. Struktur Tampilan

Struktur tampilan dari masing masing Menu diatas : File Master (Entry Data Siswa, Entry Data Kelas, Entry Jenis Biaya, Transaksi (Entry Pendataan Siswa, Entry Pembayaran SPP, Entry Pembayaran Administrasi Sekolah, Cetak Kwitansi), Laporan (Laporan Pembayaran SPP, Laporan Pembayaran Administrasi Sekolah, Laporan Tunggakan SPP)

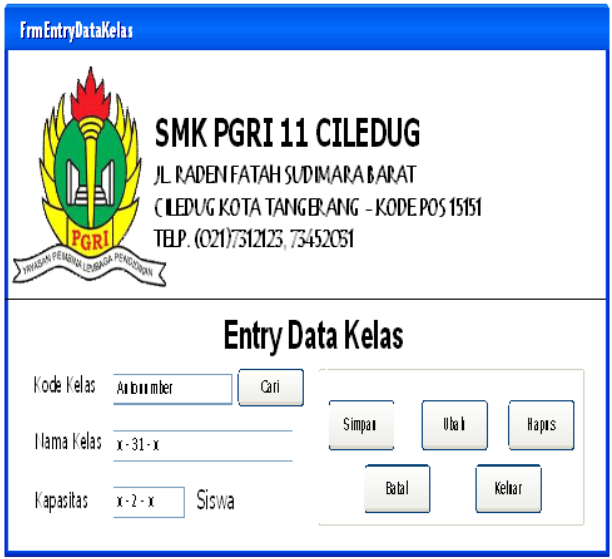

Gambar 6. Rancangan Layar Entry Data Siswa 


\section{UNISTEK, 2019, Vol. 6, No.1}

Rancangan layar Entry nomor anggota, nis, nama anggota, alamat anggota, telepon anggota, kelas, foto, dan button simpan, ubah, hapus, batal, keluar cari. Masukan Entry no anggota digunakan untuk menginput data anggota yang ada

Kolektor SPP membuka form entry data kelas, lalu Kolektor SPP menginput kelas, lalu Kolektor SPP menyimpan data kelas. Tombol hapus untuk menghapus data kelas. Tombol batal untuk membatalkan. Tombol keluar untuk keluar

\section{Kesimpulan}

Berdasarkan penelitian yang dilakukan melalui tahapan analisis, desain, pembuatan sistem dan berdasarkan uraian-uraian serta pembahasan pada bab sebelumnya, maka dapat disimpulkan beberapa hal sebagai berikut:

a. Sistem Administrasi Pembayaran SPP dan Administrasi Sekolah pada SMK PGRI 11 CILEDUG yang memanfaatkan teknologi informasi lebih mempermudah dan memperlancar proses penerimaan pembayaran.

b. Proses komputerisasi mempercepat pengolahan data dan pembuatan laporan pembayaran informasi yang dihasilkan lebih akurat, cepat, lengkap, dan bentuknya dapat dirancang sesuai dengan keinginan, sehingga dapat memperkecil kesalahan.

c. Sistem yang sudah terkomputerisasi dapat membantu mempermudah Kolektor SPP dalam pengolahan data pembayaran siswa.

d. Penyimpanan dalam database memudahkan dalam penyimpanan, pencarian dan pemeliharaan data, sehingga tidak perlu lagi menyimpan data dalam media kertas yang mudah hilang atau rusak

\section{Daftar Pustaka}

A.S, Rosa., \& Salahudin, M. (2013). Rekayasa Perangkat Lunak Tersruktur dan Berorientasi Obyek. (2013). Bandung: Informatika Bandung.

Bentley, L.D., \& Whitten, J.L. (2011). System Analysis and Design for The Global Enterprise. New york : The McGraw Hill.

Kendall, K.E., \& Kendall, J. E. (2011). Systems Analysis And Design. Pearson Education Inc: New Jersey.

Mete, S.M., \& Veiko, V.P. (1998). Laser Assisted Microtechnology, 2nd ed., R. M. Osgood, Jr., Ed. Berlin, Germany: SpringerVerlag.

R. A. Sukamto, R.A., \& Shalahuddin, M. (2013). Rekayasa Perangkat Lunak. Bandung: Informatika.

Satzinger, J. W., Jackson, R. B., \& Burd, S. D. (2012). Introduction to systems analysis and design: An agile, iterative approach. Mason, OH: Course Technology.

Tata, S. (2012). Analisis Sistem Informasi. Yogyakarta : CV Andi Offset. 